\title{
Comparison of addition of theophylline to inhaled steroid with doubling of the dose of inhaled steroid in asthma
}

\author{
D. Ukena*, U. Harnest**, R. Sakalauskas + , P. Magyar++, N. Vetter $*$ H. Steffen \\ S. Leichtls, F. Rathgeb§, A. Keller\$, V.W. Steinijans\$
}

Comparison of addition of theophylline to inhaled steroid with doubling of the dose of inhaled steroid in asthma. D. Ukena, U. Harnest, R. Sakalauskas, P. Magyar, N. Vetter, H. Steffen, S. Leichtl, F. Rathgeb, A. Keller, V.W. Steinijans. CERS Journals Ltd 1997.

ABSTRACT: The anti-asthmatic effects of theophylline may supplement those of inhaled steroids in asthma. The aim of the present trial was to study how the addition of theophylline compares to doubling the dose of inhaled steroid in asthmatics who remain symptomatic on beclomethasone dipropionate (BDP) $400 \mu \mathrm{g} \cdot \mathrm{day}^{-1}$.

The trial was designed as a randomized, double-blind, parallel-group study in several European countries. Sixty nine patients were treated for 6 weeks with theophylline plus BDP $400 \mu \mathrm{g} \cdot \mathrm{day}^{-1}$, compared to 64 patients treated with BDP $800 \mu \mathrm{g} \cdot \mathrm{day}^{-1}$. The mean \pm SD serum theophylline concentration was $10.1 \pm 4.2 \mathrm{mg} \cdot \mathrm{L}^{-1}$. Lung function measurements were made throughout the study and patients kept daily records of peak expiratory flow (PEF), symptoms and salbutamol usage.

Forced expiratory volume in one second and PEF at week 6 were significantly increased by both treatments $(p<0.01)$. PEF variability was reduced by about $30 \%$ in both groups. There were significant improvements in asthma symptoms and rescue medication use $(p<0.001)$. There were no significant differences between the treatment groups.

The study demonstrated clinical equivalence of theophylline plus beclomethasone dipropionate $400 \mu \mathrm{g} \cdot \mathrm{day}^{-1}$ and beclomethasone dipropionate $800 \mu \mathrm{g} \cdot \mathrm{day}^{-1}$ in patients

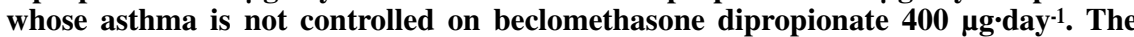
results support the use of theophylline as a steroid-sparing agent. The combination of low-dose inhaled steroid plus theophylline is a suitable treatment for moderate asthma.

Eur Respir J 1997; 10: 2754-2760.

There is growing evidence that in addition to its bronchodilatory effects, theophylline may be beneficial in the treatment of asthma through anti-inflammatory and immunomodulatory actions [1] As concluded from a withdrawal study, low-dose theophylline provided further improvement in asthma control in patients already established on high doses of inhaled corticosteroids [2]. In addition, theophylline has been shown to inhibit the late-phase response to an allergen, an effect likely to result from inhibition of allergen-induced airway inflammation [3].

Inhaled corticosteroids are a mainstay of asthma therapy. Current guidelines recommend increasing the dose of the inhaled steroid for patients whose asthma is not well controlled with low-dose inhaled steroids [4]. However, it has recently been shown that addition of long-acting inhaled $\beta_{2}$-agonists instead of higher doses of inhaled steroid may have a more beneficial role in asthma therapy [5, $6]$. The aim of the present study was to compare the addition of theophylline to increasing the dose of inhaled steroid in asthmatics who are symptomatic on low-dose inhaled steroid.
*Medizinische Universitätsklinik, Homburg, Germany; **München, Germany; +Kaunas, Litauen; ${ }^{++}$Semmelweis University of Medicine, Budapest, Hungary; ${ }^{\text {Pulmologisches }}$ Zentrum, Wien, Austria; \$tLandsberg, Germany; §Byk Gulden, Konstanz, Germany.

Correspondence: D. Ukena

Medizinische Universitätsklinik

Innere Medizin V

66421 Homburg

Germany

Keywords: Asthma

beclomethasone

inhaled steroid

theophylline

Received: August 191997

Accepted after revision October 251997

Supported by a grant from Byk Gulden, Konstanz, Germany.

\section{Methods}

This randomized, double-blind, parallel-group study was designed to examine the efficacy of beclomethasone dipropionate (BDP) $200 \mu \mathrm{g}$ b.i.d. with added theophylline capsules compared to BDP $400 \mu \mathrm{g}$ plus matched placebo capsules b.i.d. in patients with mild-to-moderate asthma. The study was conducted between October 1994 and November 1996 in several European countries. Ethics committee approvals were obtained in all countries. The study was conducted in accordance with the Good Clinical Practice Guidelines issued by the European Commission in 1990 and with the Declaration of Helsinki. All patients gave written informed consent.

\section{Patients}

All patients showed the cardinal features of asthma and fulfilled the American Thoracic Society criteria for asthma [7]. A total of 229 male and female patients aged $18-70$ yrs and not controlled on $400 \mu \mathrm{g} \cdot \mathrm{day}^{-1}$ BDP or an 
equivalent dose of another corticosteroid were recruited for the study. Entry criteria included: a) body weight of $60-100 \mathrm{~kg}$; a documented reversibility of at least $15 \%$ of forced expiratory volume in one second (FEV1) over baseline at $15 \mathrm{~min}$ after inhalation of $200 \mu \mathrm{g}$ salbutamol; FEV1 of $50-85 \%$ of predicted normal, and no severe asthma attack or lower respiratory tract infection in the month prior to the trial.

Exclusion criteria were: a history of alcohol and/or drug abuse; participation in another study within 60 days preceding the present study; a current smoker; a history of serious diseases; and concomitant use of oral corticosteroids, oral $\beta$-agonists, nedocromil, sodium cromoglycate, ketotifen and long-acting inhaled $\beta$-agonists during prospectively defined times prior to randomization.

\section{Study protocol}

A screening visit was followed by a run-in period of 1 week to a maximum of 6 weeks, randomization at baseline and a 6 week treatment period.

\section{Screening visit}

At screening, the patients underwent the following investigation: medical history, routine physical examination; laboratory work-up, including haematology and biochemistry; pulmonary function test (spirometry); and reversibility test.

Patients were then prescribed a BDP inhaler (100 $\mu \mathrm{g} \cdot$ puff $^{-1}$ ) and a spacer device and instructed to take 200 $\mu \mathrm{g}$ b.i.d. during run-in. A salbutamol inhaler was also dispensed and patients were instructed to use this as required.

Patients were issued a diary card and asked to make two entries per day of three peak expiratory flow (PEF) measurements (prior to drug intake), BDP inhalation, salbutamol usage, and symptoms. Symptom scores and salbutamol use recorded in the morning indicate events from the previous night and information recorded in the evening refers to events during the day.

For symptom scores, the following scales were used: 1) Night-time symptoms: 0: none; 1: awoke once during the night or in the early morning because of symptoms; 2 : awoke more than once during the night because of symptoms; 3: awake for a major part of the night because of symptoms, 4: awake for the whole night because of symptoms.

2) Early morning symptoms: 0: none; 1: awoke at the usual time; only minor symptoms, not disturbing; 2 : awoke at the usual time, symptoms rather disturbing; 3: awoke earlier than usual, salbutamol required before PEF measurement; 4: awoke earlier than usual; salbutamol required more than twice before PEF measurement.

3) Daytime symptoms: 0: none; 1: symptoms suffered once during a short period; 2 : symptoms suffered for most of the day, but did not interfere with usual activities; 3 : symptoms suffered for most of the day, interfering with usual activities; 4: very bad symptoms, could not go to work or do usual activities at all.

\section{Baseline and randomization}

The run-in period lasted at least 1 week and up to 6 weeks. During this period, the patients were examined once a week. Patients were randomized to treatment if, during the run-in period of at least 1 week, they fulfilled at least one of the following criteria: decrease in morning PEF by $\breve{S} 20 \%$ as compared to the value of the previous evening, on $\breve{S} 3$ of the 7 days immediately prior to randomization; nocturnal symptoms on $\breve{S} 3$ nights during the last week, with at least once having a symptom score $\breve{S} 2$; morning symptom score $\breve{S} 2$ on $\breve{S} 3$ days during the last week; daytime symptom score $\breve{S} 2$ on $\breve{S} 3$ days during the last week; $>28$ puffs of salbutamol during the last week.

Patients were randomized to receive either BDP $200 \mu \mathrm{g}$ b.i.d. plus theophylline $250 \mathrm{mg}$ b.i.d. or BDP $400 \mu \mathrm{g}$ b.i.d. with matched placebo. Following $250 \mathrm{mg}$ b.i.d. for 1 week, the theophylline maintenance dose was $375 \mathrm{mg}$ b.i.d.

\section{Study visits}

Following randomization, the patients returned to the investigational site after 1, 2, 4, and 6 weeks of treatment. At study visits, physical examination and lung function measurements were repeated and asthma exacerbations recorded. An exacerbation of asthma was defined as any worsening of asthma symptoms requiring a change in asthma therapy, other than increased use of rescue medication. Blood samples were taken for determination of the serum theophylline concentration at the final visit. Electrocardiograms (ECGs) were recorded at the beginning and end of the treatment.

All patients were obliged to return all used pop-out sachets and steroid metered-dose inhaler (MDI) devices at the study visit, after 1 week (for capsules), and after 6 weeks (for capsules and MDIs). The consumption of study medication was checked by weighing (MDIs) and counting (capsules). In addition, at each visit the patients were instructed how to use the study medication, especially the MDI with the spacer device. There were no instances of noncompliance among the patients. Throughout the study, patients kept a daily record of their morning and evening PEF (best of three measurements), daytime and night-time symptoms and use of rescue salbutamol.

\section{Drugs and laboratory analysis}

Patients were prescribed theophylline (Euphylong®, Byk Gulden, Konstanz, Germany) or matched placebo. Euphylong ${ }^{\circledR}$ has established reproducible and food-independent sustained-release pharmacokokinetic properties [8]. BDP was purchased by Glaxo (Bad Oldesloe, Germany). Inhalers were of identical appearance in both treatment groups.

Serum theophylline concentrations were determined using a photometric assay (Bayer, Leverkusen, Germany).

\section{Statistical analysis}

The primary outcome variable was the improvement in PEF at 6 weeks over baseline. More precisely, the mesor PEF (average of morning and evening PEF) was calculated from diary cards during the respective period prior to 
the scheduled visit. As baseline, the values from the week prior to randomization were used. Since both groups received active treatment, it was appropriate to test whether the theophylline/BDP $400 \mu \mathrm{g} \cdot \mathrm{day}^{-1}$ (test) was at least equivalent to the BDP $800 \mu \mathrm{g} \cdot \mathrm{day}^{-1}$ (reference). To this end, geometric mean and $95 \%$ confidence intervals $(95 \%$ CI) were calculated for the test/reference ratio of baseline-adjusted population medians. At least equivalence was concluded if the lower limit of the $95 \%$ CI was above the equivalence acceptance limit of 0.90 , which had been chosen in accordance with clinical requirements [9]. The statistical procedure ensured that the risk of incorrectly concluding equivalence was limited to 5\% [10]. With the additional assumption of equality of the population medians and a $15 \%$ coefficient of variation for the ratio of PEF measurements on week 6/PEF measurements at baseline, a minimum of 52 patients per group resulted in $80 \%$ statistical power for showing at least equivalence [11].

Time courses of lung function variables (PEF, FEV1) are presented as mean \pm SEM. In view of the add-on treatment in both groups, a one-sided approach appeared to be justified for the secondary comparisons at the four visits within a treatment group. These were done by the onesided paired t-test. In case of percentage change, a logarithmic transformation of the data was performed. Due to multiple testing, the Bonferroni-Holm correction was applied [12].

Other response variables from the diary card such as asthma symptoms or number of salbutamol puffs during the respective periods were also averaged between scheduled visits, and characterized by the median. Pre-/postcomparisons within a treatment group were conducted with the one-sided Wilcoxon matched pairs signed rank test, while the comparison between treatment was conducted with the two-sided Mann-Whitney U-Test; $\alpha=0.05$ was considered as relevant. Therefore, a p-value of less than or equal to 0.05 was considered significant.

\section{Results}

Of the 229 patients recruited, 190 were randomized to treatment. One hundred patients were randomized to theophylline plus BDP $400 \mu \mathrm{g} \cdot$ day $^{-1}$ and 90 patients to BDP $800 \mu \mathrm{g} \cdot$ day $^{-1}$. The main reason for withdrawal prior to randomization was ineligibility. After randomization, seven patients were withdrawn due to adverse events (six from the theophylline/BDP group and one from the BDP 800 $\mu \mathrm{g} \cdot$ day $^{-1}$ group), and one from the theophylline/BDP group due to exacerbation of asthma. The other 49 withdrawals were due to: violation of inclusion criteria $(n=37)$; nonmedical reasons $(n=10)$; and medical reasons $(n=2)$. Withdrawals were evenly distributed between the two treatment groups. Sixty nine patients in the theophylline/BDP group and 64 patients in the BDP $800 \mu \mathrm{g}$ group completed the study according to the protocol and had valid measurements of the primary variable at baseline and week 6 . These data were used in the efficacy analysis on a per-protocol and keypoint-available basis. In addition, an intention-to-treat analysis was performed (data not shown, with the exception of the adverse events), which gave nearly identical results and confirmed the statistical conclusions derived from per-protocol analysis.
The groups were well matched for all demographic details (table 1). With respect to the randomization criteria, proportions of patients experiencing nocturnal symptoms, early morning symptoms, daytime symptoms, use of relief medication and PEF variability in the week prior to randomization are summarized in table 2 . In the theophylline/BDP group, the serum concentrations of theophylline were $10.1 \pm 4.2 \mathrm{mg} \cdot \mathrm{L}^{-1}($ mean $\pm \mathrm{SD})$.

\section{Home PEF recordings}

Mean morning and evening PEF increased from baseline in both groups within the first week of treatment (fig. 1). These increases were statistically significant at all time points even after the Bonferroni-Holm correction (morning: pð0.001, evening: pð0.02). The increases in the theophylline plus BDP $400 \mu \mathrm{g} \cdot \mathrm{day}^{-1}$ group were generally

Table 1. - Baseline characteristics of the patients in the two treatment groups

\begin{tabular}{lccc}
\hline \multirow{2}{*}{ Parameter } & & Theo/BDP & BDP \\
& & $400 \mu \mathrm{g} \cdot$ day $^{-1}$ & $800 \mu \mathrm{g} \cdot$ day $^{-1}$ \\
\hline Patients n & & 69 & 64 \\
Sex M/F & & $37 / 32$ & $38 / 26$ \\
Age yrs & & $48^{*}(20-70)$ & $49^{*}(18-70)$ \\
FEV1 & L & $2.30 \pm 0.62$ & $2.40 \pm 0.75$ \\
& $\%$ pred & $74 \pm 16$ & $76 \pm 13$ \\
FEV1 response salbutamol & $28.5 \pm 14.6$ & $28.6 \pm 15.7$ \\
\% change over baseline & $345 \pm 95$ & $344 \pm 105$ \\
Morning PEF & L.min ${ }^{-1}$ & $(113-540)$ & $(154-550)$ \\
& & $77 \pm 20$ & $75 \pm 18$ \\
Evening PEF & L.min ${ }^{-1}$ & $368 \pm 106$ & $368 \pm 110$ \\
& & $(110-630)$ & $(168-633)$ \\
Mesor PEF & L.min ${ }^{-1}$ & $356 \pm 99$ & $356 \pm 106$ \\
& & $(111-584)$ & $(162-587)$ \\
& $\%$ pred & $79 \pm 20$ & $78 \pm 17$ \\
PEF variability $\%$ & $10.1 \pm 6.8$ & $10.1 \pm 6.3$ \\
\hline
\end{tabular}

Data are presented as mean \pm SD with range in parenthesis. *: median. Theo: theophylline; BDP: beclomethasone dipropionate; M: male; F: female; FEV1: forced expiratory volume in one second; PEF: peak expiratory flow; Mesor PEF: average of morning and evening PEF; PEF variability: (maximum PEF minimum $\mathrm{PEF}$ )/maximum PEF; \% pred: percentage of predicted values.

Table 2. - Randomization criteria

\begin{tabular}{|c|c|}
\hline Criterion & $\begin{array}{l}\text { Patients } \\
\mathrm{n}(\%)\end{array}$ \\
\hline $\begin{array}{l}\text { Š3 nights during the last week with asthma } \\
\text { symptoms, with at least once a symptom score Š2 }\end{array}$ & $75(56)$ \\
\hline $\begin{array}{l}\text { Morning symptoms score } \breve{S} 2 \text {, on } \breve{S} 3 \text { days during } \\
\text { the last week }\end{array}$ & $67(50)$ \\
\hline $\begin{array}{l}\text { Daytime symptom score } \breve{S} 2 \text { on } \breve{S} 3 \text { days during } \\
\text { the last week }\end{array}$ & $76(57)$ \\
\hline \multicolumn{2}{|l|}{$>28$ puffs of salbutamol during the last week } \\
\hline $\begin{array}{l}\text { Decrease in morning PEF by } \check{S} 20 \% \text { as compared } \\
\text { to the value of the previous evening, on } \breve{S} 3 \text { days }\end{array}$ & $60(45)$ \\
\hline during the last & $27(20)$ \\
\hline
\end{tabular}

PEF: peak expiratory flow. 

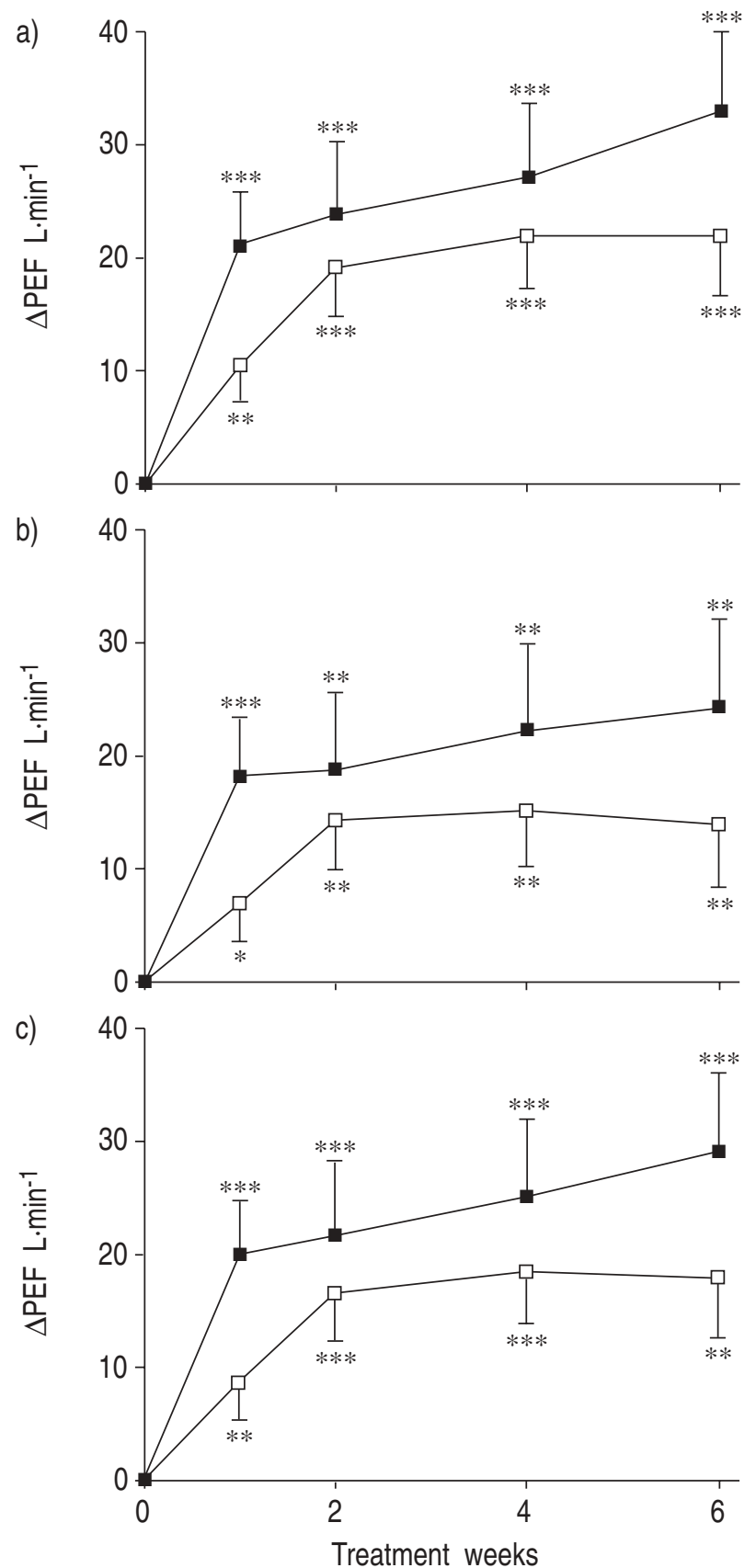

Fig. 1. - Changes $(\Delta)$ in home peak expiratory flow (PEF). a) morning PEF; b) evening PEF; c) (morning PEF+evening PEF)/2. $\square$ : patients treated with beclomethasone dipropionate (BDP) $800 \mu \mathrm{g} \cdot \mathrm{day}^{-1} \quad(\mathrm{n}=64)$; - : patients treated with theophylline/BDP $400 \mu \mathrm{g} \cdot \mathrm{day}^{-1}(\mathrm{n}=69)$. Values are presented as mean \pm sev. $*: \mathrm{p}<0.05 ; * *: \mathrm{p}<0.01 ; * * *: \mathrm{p}<0.001$, compared to baseline (unadjusted p-values).

greater than in the BDP $800 \mu \mathrm{g} \cdot \mathrm{day}^{-1}$ group. The maximum PEF increases in the theophylline/BDP group were $33 \mathrm{~L} \cdot \mathrm{min}^{-1}$ in the morning and $24 \mathrm{~L} \cdot \mathrm{min}^{-1}$ in the evening, compared to $22 \mathrm{~L} \cdot \mathrm{min}^{-1}$ and $15 \mathrm{~L} \cdot \mathrm{min}^{-1}$, respectively, in the BDP $800 \mu \mathrm{g} \cdot$ day $^{-1}$ group. Comparison between treatments with regard to the improvement in morning and evening PEF at week 6 showed that theophylline plus BDP 400 $\mu \mathrm{g} \cdot \mathrm{day}^{-1}$ was at least equivalent to BDP $800 \mu \mathrm{g} \cdot$ day $^{-1}$ (test/ reference ratio: 1.02 and 1.03, respectively; one-sided $95 \%$ CI was 0.98 in both cases, clearly exceeding the equivalence acceptance limit of 0.90 ).

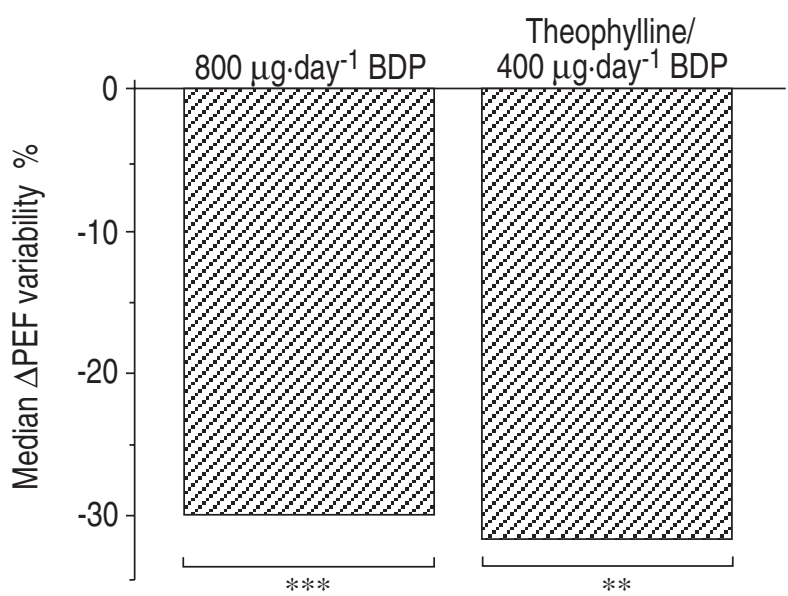

Fig. 2. - Median change $(\Delta)$ in peak expiratory flow (PEF) variability after 6 weeks of treatment, beclomethasone dipropionate (BDP) 800 $\mu \mathrm{g} \cdot \mathrm{day}^{-1}(\mathrm{n}=64)$ or theophylline/BDP $400 \mu \mathrm{g} \cdot \mathrm{day}^{-1}(\mathrm{n}=69)$. PEF variability $=($ maximum PEF - minimum PEF $) /$ maximum PEF. **: $p<0.01$; $* * *: \mathrm{p}<0.001$, compared to baseline.

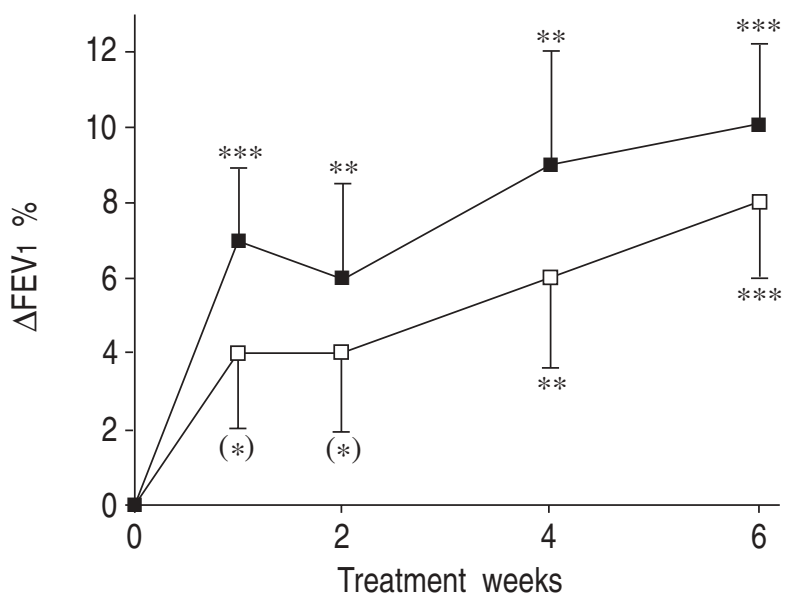

Fig. 3. - Percentage change in forced expiratory volume in one second $(\triangle \mathrm{FEV} 1)$ measured at clinic visits. $\square$ : patients treated with beclomethasone dipropionate (BD) $800 \mu \mathrm{g} \cdot \mathrm{day}^{-1} ; \boldsymbol{m}$ : patients treated with theophylline/BDP $400 \mu \mathrm{g} \cdot$ day $^{-1} ; *$ : $\mathrm{p}<0.05 ; * *: \mathrm{p}<0.001 ; * * * \mathrm{p}<0.001$, compared to baseline (unadjusted p-values; those in parenthesis were not significant after Bonferroni-Holm adjustment).

Throughout the study, the median PEF variability improved significantly compared to baseline in both treatment groups. After 6 weeks of treatment, PEF variability was reduced by $29.9 \%$ in the BDP $800 \mu \mathrm{g} \cdot \mathrm{day}^{-1}$ group, and by $31.8 \%$ in the theophylline/BDP $400 \mu \mathrm{g} \cdot \mathrm{day}^{-1}$ group (fig. 2 ). There was no statistically significant difference between treatments $(\mathrm{p}=0.960)$.

\section{Clinical lung function}

For both treatment groups, there was an improvement in FEV1 after 1 week of treatment, which further increased throughout the study (fig. 3). In the theophylline/ BDP $400 \mu \mathrm{g} \cdot$ day $^{-1}$ group the mean FEV1 value increased from a baseline of $2.30 \pm 0.62 \mathrm{~L}$ to $2.56 \pm 0.74 \mathrm{~L}$ at week 6 . In the BDP $800 \mu \mathrm{g} \cdot \mathrm{day}^{-1}$ group, FEV1 increased from $2.40 \pm 0.75 \mathrm{~L}$ to $2.59 \pm 0.78 \mathrm{~L}$ at the end of treatment period. In the theophylline/BDP $400 \mu \mathrm{g} \cdot$ day $^{-1}$ group the increases 
in FEV1 were statistically significant at all time points (pð0.009), whereas in the BDP $800 \mu \mathrm{g} \cdot \mathrm{day}^{-1}$ group the changes were significant after the Bonferroni-Holm correction only at weeks 4 and 6 (pð0.007). Comparison between treatments confirmed equivalence with regard to the improvement in FEV1 at week 6 (test/reference ratio 1.02; one-sided $95 \%$ CI 0.97 , clearly exceeding the equivalence acceptance limit of 0.90 ).

\section{Symptoms and use of relief medication}

Symptom scores improved significantly in both treatment groups $(\mathrm{p}<0.001)$. Compared to the treatment with BDP $400 \mu \mathrm{g} \cdot \mathrm{day}^{-1}$ in the run-in period, there was a marked reduction of asthma symptoms during the day and the night after 6 weeks of treatment with either theophylline/ BDP $400 \mu \mathrm{g} \cdot \mathrm{day}^{-1}$ or BDP $800 \mu \mathrm{g} \cdot \mathrm{day}^{-1}$ (fig. 4). There was no statistically significant difference between treatments (day: $\mathrm{p}=0.575$; night: $\mathrm{p}=0.196$ ).

In accordance with the clinical improvement, daytime and night-time use of relief medication decreased significantly in both treatment groups (fig. 5). There was no statistically significant difference between treatments (day: $\mathrm{p}=0.392$; night: $\mathrm{p}=0.814$ ).
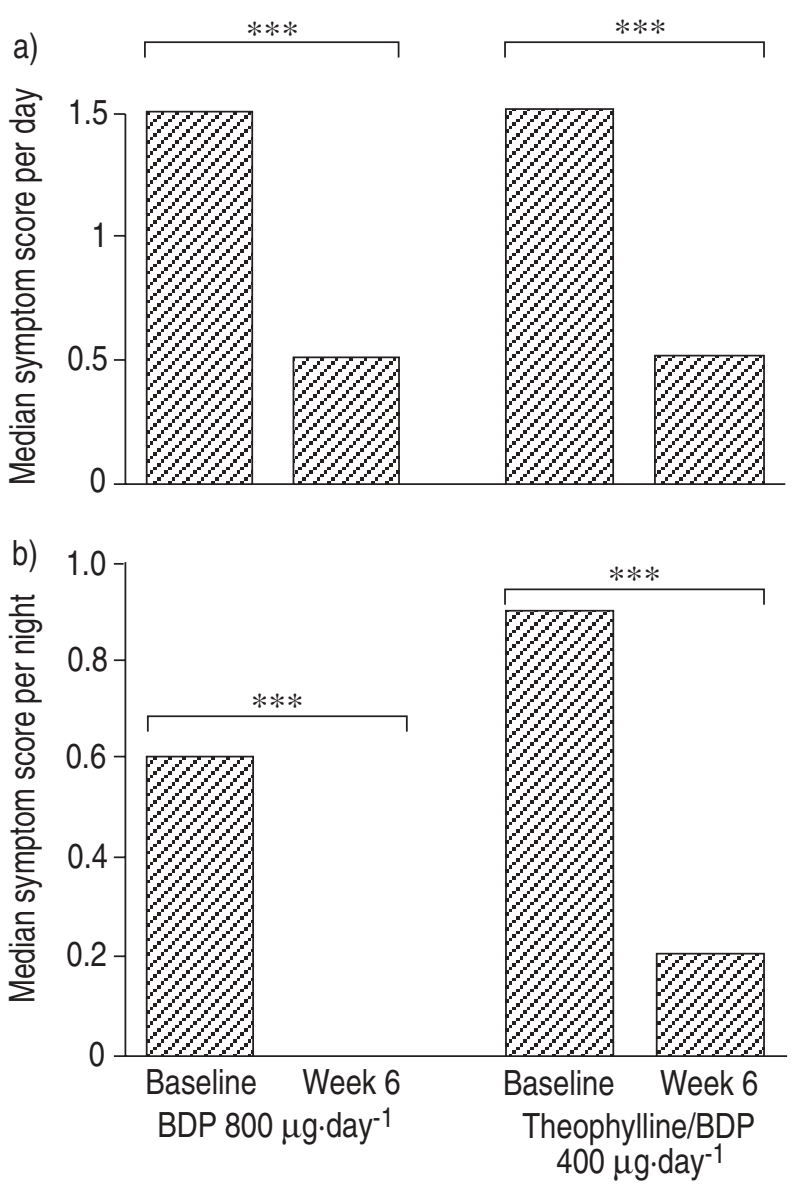

Fig. 4. - Median patient symptom score; a) day; and b) night, from diary cards (average during last week of the run-in period, baseline) and during the last 2 weeks of the treatment period (week 6) for patients treated with either beclomethasone dipropionate (BDP) $800 \mu \mathrm{g} \cdot \mathrm{day}^{-1}$ $(\mathrm{n}=64)$ or theophylline/BDP $400 \mu \mathrm{g} \cdot \mathrm{day}^{-1}(\mathrm{n}=69)$. ***: $\mathrm{p}<0.001$.
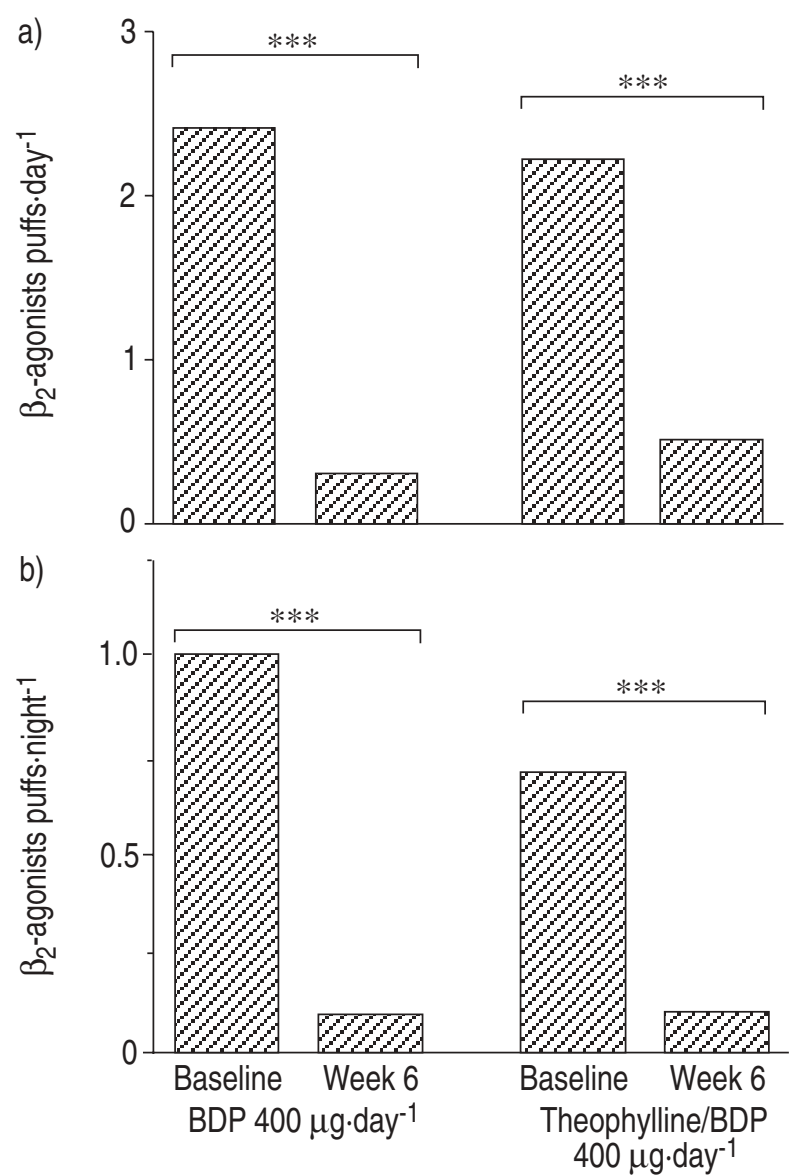

Fig. 5. - Median number of puffs of rescue medication per: a) day (9:00-24:00 h) and b) night (0:00-9:00 h), from the diary cards. BDP: beclomethasone dipropionate. $* * *: \mathrm{p}<0.001$.

\section{Adverse events}

In general, both treatment regimens were well tolerated. Reporting of adverse events refers to the intention- to-treat group. No serious adverse event was reported. Twenty seven adverse events, which were either pharmacological predictable or attributable to asthma, were observed in the theophylline/BDP group (15 gastro-intestinal symptoms, six palpitations, and six respiratory symptoms such as dyspnoea or cough), and 17 events were observed in the BDP $800 \mu \mathrm{g}$ group (four gastro-intestinal symptoms, two palpitations, and 11 respiratory symptoms). In addition, a further 23 adverse events in the theophylline/BDP group and 12 events in the BDP $800 \mu \mathrm{g} \cdot \mathrm{day}^{-1}$ group were reported comprising myalgia, nonrespiratory bacterial infections, and weakness.

\section{Discussion}

The present study demonstrates clinical equivalence of theophylline plus BDP $400 \mu \mathrm{g} \cdot \mathrm{day}^{-1}$ compared to BDP 800 $\mu \mathrm{g} \cdot \mathrm{day}^{-1}$ in patients whose asthma is not controlled on BDP $400 \mu \mathrm{g} \cdot$ day $^{-1}$. This result supports the use of theophy-lline as a steroid-sparing agent in the treatment of asthma [1].

The combination of low-dose inhaled corticosteroid and theophylline appears to be intriguing for several rea- 
sons. Corticosteroids and theophylline act via different molecular mechanisms. Inhaled corticosteroids suppress the inflammation in asthmatic airways by targeting many different types of inflammatory cells in the airways [13, 14]. The molecular basis for this anti-inflammatory effect is most likely to be the reduced transcription of inflammatory proteins such as cytokines, adhesion molecules, inflammatory enzymes and inflammatory receptors $[13$, 14]. This may be achieved in part by direct inhibition of transcription factors such as activator protein 1 (AP-1) and nuclear factor $(\mathrm{NF})-\kappa \mathrm{B}$ that amplify and perpetuate the inflammatory process in asthmatic airways [13, 14].

While the bronchodilator effect of theophylline is almost certainly due to inhibition of phosphodiesterase activities in airway smooth muscle, the anti-inflammatory effects may be mediated via additional and unidentified mechanisms $[1,15,16]$. The xanthine may have several anti-inflammatory actions in the airways, and these may be mediated in part outside the airways $[1,15,16]$. Based on the different molecular mechanisms, the anti-inflammatory effects of theophylline may supplement those of inhaled corticosteroids in asthma. Indeed, short-term studies provided evidence that theophylline improves lung function when added to oral or inhaled steroid in moderate to severe asthma [17-19].

Another rationale for the combination of inhaled corticosteroids and theophylline is related to the shape of the dose-response curve of inhaled steroids. After an initial marked effect of the lowest dose of inhaled steroid, the mean dose-response curve is rather shallow at least for the most commonly used outcomes including symptoms, PEF, FEV1 and other measures of lung function [20-22]. In addition, since the clinical significance of unwanted systemic effects of inhaled steroids in the commonly used dose range is currently under debate, titration of the dose of inhaled steroid to the lowest possible long-term level is recommended to minimize the risk of unwanted systemic effects $[20,23,24]$. This suggests that increasing the dose of inhaled steroids in patients not well controlled on low doses may not provide as much benefit as addition of a drug such as theophylline with different profiles of beneficial effects and unwanted effects.

The present study shows that treatment with either theophylline/BDP $400 \mu \mathrm{g} \cdot \mathrm{day}^{-1}$ or BDP $800 \mu \mathrm{g} \cdot \mathrm{day}^{-1}$ resulted in significant and comparable improvements in lung function. Data for PEF and FEV1 showed equivalence of the treatments. There were also significant and comparable improvements concerning asthma symptoms and rescue medication use.

Since inflammatory parameters were not examined in the present study, it is not possible to conclude antiinflammatory actions of theophylline. Some observations, however, may indicate such a mechanism. With both treatments, there was an approximately $30 \%$ reduction in PEF variability. This is an important aspect as PEF variability is a marker of bronchial hyperresponsiveness and asthma severity [25]. In addition, the delayed improvement in lung function is characteristic of controller drugs used in the treatment of asthma, whereas bronchodilatation induced for instance by $\beta$-sympathomimetics is characterized by rapid improvements in lung function. More studies are needed to explore the mechanism of interaction between theophylline and inhaled corticosteroids.
The results of the present study are comparable with those of a recently published abstract [26]. In the latter study, 62 patients were treated for 3 months with theophylline/budesonide $800 \mu \mathrm{g} \cdot \mathrm{day}^{-1}$ or budesonide $1,600 \mu \mathrm{g}$. day $^{-1}$. The median serum concentration of theophylline was $8.7 \mathrm{mg} \cdot \mathrm{L}^{-1}$. There were greater increases in lung function for the patients treated with theophylline/low-dose budesonide for forced vital capacity $(\mathrm{FVC} ; \mathrm{p}=0.03$ ) and FEV1 ( $\mathrm{p}=0.03)$. The improvements in $\beta_{2}$-agonist use and PEF variability were comparable in both treatment groups. It is worth noting that low-dose theophylline achieved this without any adverse effect, whereas the higher dose of budesonide was associated with a significant reduction in morning plasma cortisol levels [26]. In the present study, there were more numerous adverse effects in the theophylline-treated group. As is characteristic for theophylline, mild, transient gastro-intestinal disturbances were observed more often in the theophylline/BDP $400 \mu \mathrm{g} \cdot$ day $^{-1}$ group than in the BDP $800 \mu \mathrm{g} \cdot$ day $^{-1}$ group.

The results of this trial and the data from the present study indicate that the combination of inhaled steroid $400-800 \mu \mathrm{g} \cdot$ day $^{-1}$ plus theophylline is at least as effective as doubling the dose of inhaled steroids in patients who remain symptomatic on inhaled steroid 400-800 $\mu \mathrm{g} \cdot \mathrm{day}^{-1}$. These effects of theophylline are achievable at serum concentrations in the lower range of the therapeutic window minimizing side-effects [1].

The results of both theophylline/inhaled steroid studies are compatible with trials examining the effects of added salmeterol to inhaled steroid. In these trials with several hundred patients, the addition of salmeterol provided more improvement in lung function and symptom control than did doubling the dose of BDP $[5,6]$. Bronchodilatation is the most likely explanation for benefits seen in both salmeterol studies. In contrast to theophylline, there is no evidence for an anti-inflammatory effect of salmeterol. Accordingly, salmeterol plus low-dose inhaled steroid did not reduce PEF variability, as observed for the theophylline/BDP $400 \mu \mathrm{g} \cdot$ day $^{-1}$ group in the present study. Additionally, in contrast to the present study, there were no increases in PEF and FEV1 in the groups of patients treated with high-dose inhaled steroid alone in both salmeterol studies [5, 6].

The addition of theophylline to low-dose inhaled steroid rather than doubling the dose of inhaled steroid is also of importance with respect to the pharmacoeconomics of asthma therapy [27]. Since theophylline is probably the cheapest antiasthma drug available worldwide, the combination of theophylline with low-dose inhaled steroid could lead to considerable savings in expenditure for the management of asthma.

Our study has demonstrated clinical equivalence of theophylline/beclomethasone dipropionate $400 \mu \mathrm{g} \cdot \mathrm{day}^{-1}$ to beclomethasone dipropionate $800 \mu \mathrm{g} \cdot \mathrm{day}^{-1}$ in the control of asthma. The addition of theophylline to low-dose inhaled steroid therapy is a suitable alternative to doubling the dose of inhaled steroid for patients with asthma who are not adequately controlled on low-dose inhaled steroid.

Acknowledgements: The authors would like to thank C. Schmid and T. Hummel, for the clinical monitoring and data management, and M. Neuhäuser for valuable comments. The contributions to the study made by the following pneumologists are thankfully acknowledged: Austria: K. Harnoncourt, 
Graz; R. Holzer, Wiener Neustadt; N. Kaufmann, Graz; Germany: B. Koemer, Kaufbeuren; T. Straus, Bayreuth; M. Barczok, Ulm; R. Sauer, Ulm; K.O. Steinmetz, Darmstadt; I. Szasz, Stuttgart; T. Menzel, Hamburg; D. Rost, Augsburg; W. Lutz, Neunkirchen; U. Trendelenburg, Saarbrücken; H. Grygier, Bad Homburg; M. Quidan, Frankfurt; H. Trauth, Marburg; J. Lehnert, München; J. Besch, Neunkirchen; H. Olbrich, Augsburg; C. Uhde, München; W. Pfeifer, Kempten; W. Feußner, Kassel; B. Rosenblum, Stuttgart; N. Peslis, Eschwege; Hungary: G. Böszörmenyi Nagy, Budapest.

\section{References}

1. Barnes PJ, Pauwels RA. Theophylline in the management of asthma: time for reappraisal? Eur Respir J 1994; 7 : 579-591.

2. Kidney J, Dominguez M, Taylor PM, Rose M, Chung KF, Barnes PJ. Immunomodulation by theophylline in asthma: demonstration by withdrawal of therapy. Am J Respir Crit Care Med 1995; 151: 1907-1914.

3. Sullivan PJ, Bekir S, Jaffar Z, Page C, Jeffery P, Costello J. Anti-inflammatory effects of low-dose theophylline in atopic asthma. Lancet 1994; 343: 1006-1008.

4. International Consensus Report on Diagnosis and Management of Asthma. National Heart, Lung and Blood Institute, National Institutes of Health, Bethesda, MD, March 1992. Publication No. 92-3091.

5. Woolcock A, Lundback B, Ringdahl N, Jacques LA. Comparison of addition of salmeterol to inhaled steroids with doubling of the dose of inhaled steroids. Am J Respir Crit Care Med 1996; 153: 1481-1488.

6. Greening AP, Ind PW, Northfield M, Shaw G. Added salmeterol versus higher-dose corticosteroid in asthma patients with symptoms on existing inhaled corticosteroid. Lancet 1994; 344: 219-224.

7. American Thoracic Society report on chronic bronchitis, asthma, and pulmonary emphysema. Am Rev Respir Dis 1987; 136: 224-225.

8. Steinjans VW, Sauter R, Böhm A, Staudinger H. Pharmacokinetic profile of a new sustained-release theophylline pellet formulation for once-daily evening administration. Drug Research 1988; 38: 1241-1250.

9. Steinijans VW. Statistical evaluation of comparative clinical trials: what are the methods of choice. Henry-Stewart Conference on "Understanding Equivalence Testing for Inhaled Drugs", London, June 20, 1997. Conference report in preparation).

10. European Agency for the Evaluation of Medicinal Products. Human Medicines Evaluation Unit. Note for Guidance on Statistical Principles for Clinical Trials (CPMP/ ICH/363/96). ICH Topic E9, Statistical Principles for Clinical Trials, Step 3. January 17, 1997.
11. Elashoff JD. NQUERY Advisor User's Guide. Los Angeles, CA, Dixon Associates, 1995.

12. Holm S. A simple sequentially rejective multiple test procedure. Scand J Statist 1979; 6: 65-70.

13. Barnes PJ, Pedersen S. Efficacy and safety of inhaled corticosteroids in asthma. Am Rev Respir Dis 1993; 148: S1S26.

14. Barnes PJ, Adcock I. Anti-inflammatory actions of steroids: molecular mechanisms. Trends Pharmacol Sci 1993; 14: 436-441.

15. Rabe KF, Magnussen H, Dent G. Theophylline and selective PDE inhibitors as bronchodilators and smooth muscle relaxants. Eur Respir J 1995; 8: 637-642.

16. Banner KH, Page CP. Theophylline and selective phosphodiesterase inhibitors as anti-inflammatory drugs in the treatment of bronchial asthma. Eur Respir J 1995; 8: 996-1000.

17. Prowse K, Walters EH. Can theophylline reduce the need for oral corticosteroids? J Int Med Research 1979; 7 : 101-105.

18. Nassif EG, Weinberger M, Thompson R, Huntley W. The value of theophylline in steroid-dependent asthma. $N$ Engl J Med 1981; 304: 71-75.

19. Rivington RN, Boulet L-P, Cote J, et al. Efficacy of Uniphyl囚, albutamol, and their combination in asthmatic patients on high-dose inhaled steroids. Am J Respir Crit Care Med 1995; 151: 325-332.

20. Pedersen S, O'Byrne P. A comparison of the efficacy and safety of inhaled corticosteroids in asthma. Allergy 1997; 52 (Suppl. 39): 1-34.

21. Busse W. Dose-related efficacy of Pulmicort ${ }^{\circledR}$ (BUD) Turbuhaler ${ }^{\circledR}$ in moderate to severe asthma. J Allergy Clin Immunol 1994; 93 (Suppl.): 186.

22. Dahl R, Lundbäck B, Malo JM, et al. A dose-ranging study of fluticasone propionate in adult patients with moderate asthma. Chest 1993; 104: 352-358.

23. Barnes PJ. Inhaled glucocorticoids for asthma. $N$ Engl $J$ Med 1995; 332: 868-875.

24. Geddes DM. Inhaled corticosteroids: benefits and risks. Thorax 1992; 47: 404-407.

25. Ryan G, Latimer KM, Dolovich J, Hargreave FE. Bronchial responsiveness to histamine. relationship to diurnal variation of peak flow rate, improvement after bronchodilator, and airway calibre. Thorax 1982; 37: 423-429.

26. Evans DJ, Taylor DA, Keller A, et al. Low dose inhaled steroid plus theophylline $v s$. high dose inhaled steroid in the control of asthma. Am J Respir Crit Care Med 1997; 155: A202.

27. Barnes PJ, Jonsson B, Klim JB. The cost of asthma. Eur Respir J 1996; 9: 636-642. 